\title{
Equation of State of Forsterite ${ }^{1}$
}

\author{
Thomas J. Ahrens, John H. Lower, and Peter L. Lagus \\ Seismological Laboratory, California Instilute of Technology, Pasadena 91109
}

\begin{abstract}
Shock wave data for pure forsterite with initial bulk densities of 2.6 and $3.1 \mathrm{~g} / \mathrm{cm}^{3}$ are obtained to $0.370 \mathrm{Mb}$ by impacting series of specimens with tungsten alloy plates that are launched at speeds of up to $2.3 \mathrm{~km} / \mathrm{sec}$ with a high-performance propellant gun. The onset of a shock-induced phase change, probably corresponding to the forsterite-'post spinel' phase change is observed at $0.280 \pm 0.025 \mathrm{Mb}$. Because of the low shock temperatures, the transition is believed to be limited by the reaction rate and this pressure value should be taken only as an upper limit. Adiabats derived from the Hugoniot data for the forsterite phase are fit to the two-parameter finite strain Birch-Murnaghan equation and to two simple ionic equations of state. The BirchMurnaghan form of the equation of state gives a zero-pressure bulk modulus (1.29 Mb) that agrees more closely with the ultrasonic data than the modulus obtained from the ionic equations of state. An unusual relaxation effect, in which the elastic shock precursor velocity varies from 5.8 to $9.5 \mathrm{~km} / \mathrm{sec}$, is also observed. The characteristic time of the relaxation process appears to be less than $1 \mu$ sec.
\end{abstract}

The equation of state of the pure magnesium end member of the olivine series, forsterite, $\mathrm{Mg}_{2} \mathrm{SiO}_{4}$, plays a key role in the application of seismological and high-pressure ultrasonic and phase equilibrium data to investigation of the mineralogies and temperatures within the earth's upper mantle [Birch, 1952; Anderson, 1967; Ringwood, 1969]. In addition to the early pressure-density data of Bridgman [1948], complete elastic constant data to $400^{\circ} \mathrm{C}$ and $10 \mathrm{~kb}$ have recently been obtained ultrasonically on nearly pure crystals by Graham and Barsch [1969] and Kumazawa and Anderson [1969]. The previous shock-wave equation of state measurements of Hughes and McQueen [1958], McQueen et al. [1967], Trunin et al. [1966], and Ahrens and Petersen [1969] for various dunites have been useful in delineating the onset of a shock-induced phase change and, in some cases, the equation of state of a shock-induced high-pressure phase. For the dunites the shock-induced high-pressure phase has an apparent zero-pressure material density close to the density of an isochemical mix of the close-packed oxides $\mathrm{SiO}_{2}$ (stishovite), $\mathrm{MgO}$, and $\mathrm{FeO}$. From the static high-pressure quenching experiments of Ringwood and Major [1970] it appears that at $1000^{\circ} \mathrm{C}$ pure forsterite

${ }^{1}$ Contribution 1775, Division of Geological Sciences, California Institute of Technology.

Copyright (c) 1971 by the American Geophysical Union. transforms to the distorted spinel or $\beta$ olivine form (zero-pressure density, $3.48 \mathrm{~g} / \mathrm{cm}^{3}$ ) at $\sim 145 \mathrm{~kb}$, the pure spinel phase of $\mathrm{Mg}_{2} \mathrm{SiO}_{4}$ $\left(3.55 \mathrm{~g} / \mathrm{cm}^{3}\right)$ occurs at still higher pressures. Ahrens and Syono [1967] and Anderson [1967] have shown that above $\sim 200 \mathrm{~kb}$ the pure spinel phase is unstable with respect to the denser oxides. On the basis of quenching experiments on analog compounds Ringwood and Reid [1968] have suggested that the 'post-spinel' phase of forsterite has the structure of either $\mathrm{K}_{2} \mathrm{NiF}_{4}$ or $\mathrm{Sr}_{2} \mathrm{PbO}_{4}$. The inferred zero-pressure density of the high-pressure shocked phases of the dunites [Ahrens et al., 1969], as well as the presumably ferromagnesium material of the mantle at depths below $900 \mathrm{~km}(\sim 300 \mathrm{~kb})$, is consistent with one of these structures [Anderson, 1970]. In addition to the data for dunites, a series of six Hugoniot points for the high-pressure phase of a ceramic forsterite has been obtained by McQueen and Marsh and is given in Clark [1966].

To obtain additional data on the equation of state and the onset of the shock-induced phase change in forsterite, we have conducted a series of shock-wave experiments on this material. Because of the stability of forsterite over a wide range of pressures under shock conditions, the apparent absence of significant strength effects, and the availability of precision ultrasonic data at low pressure, we have also fit the present data with several equations of state. 


\section{Specimen Materials}

Polycrystalline forsterite obtained from Muscle Shoals Electrochemical Corporation was used to fabricate most of the specimens in the present study. This material, which is slightly porous, was fused from the oxides. It is light gray in appearance and has tabular grains $0.5-2 \mathrm{~mm}$ long. It came to us in grapefruit-sized pieces that were cored and sawed into 80 disks that were $22 \mathrm{~mm}$ in diameter and 4 or $6 \mathrm{~mm}$ thick. On the basis of visual and radiographic inspection 25 samples that were free from cracks, large pores, and obvious inclusions were finally used as specimens. Although the thin sections showed no phases other than forsterite to be present, a series of X-ray (shadowgraph) radiographs of some of the specimens showed them to contain a few $\sim 0.1$-mm-thick slivers of a dense phase believed to be FeSi (density, $6.1 \mathrm{~g} / \mathrm{cm}^{3}$ ). Using the apparent areas of the inclusion shown on the radiographs and assuming random orientation, we calculated that these slivers occupied about $0.02 \%$ of the sample volume; hence, they increased the bulk density by $\sim 0.04 \%$. Microprobe analysis (Table 1) of the forsterite phase indicates that this material is stoichiometric and nearly iron free within the detectable limits of the instrument $(\sim \pm 0.5 \%)$. Using Graham and Barsch's [1969] value of $3.2217 \mathrm{~g} / \mathrm{cm}^{\mathrm{g}}$ for the density of forsterite and correcting for FeSi inclusions, we adopted a value of $3.223 \mathrm{~g} / \mathrm{cm}^{3}$ for the zero-pressure crystal density of this material.

After machining the specimen to tolerances of $\pm 0.005 \mathrm{~mm}$ and removing cutting solvents in an ultrasonic cleaner, the samples were weighed and their dimensions recorded. Volume corrections of up to $0.01 \%$ were applied to take account of chips removed in the grinding process. The bulk density of all the specimens was deter-

TABLE 1. Composition of Muscle Shoals Synthetic Forsterite

\begin{tabular}{cc}
\hline Element & Formula Proportions \\
\hline $\mathrm{Mg}$ & 2.03 \\
$\mathrm{Al}$ & 0.001 \\
$\mathrm{Si}$ & 0.983 \\
$\mathrm{Fe}$ & 0.0004 \\
\hline
\end{tabular}

Composition determined by electron microprobe method, A. Albee and A. Chodos. mined to within $\pm 0.009 \mathrm{~g} / \mathrm{cm}^{3}$ (Table 2). This uncertainty is wholly attributed to uncertainty in the volume determination.

In addition to the fusion cast material, three shots were fired at low pressure with a pressed aggregate of fosterite purchased from Atomergic Corp. This material had a bulk density of 2.6 $\mathrm{g} / \mathrm{cm}^{3}$. Although binding agents were not used in preparing the samples, thin sections and electron microprobe scans indicated that a small amount of an isotropic aluminum-bearing phase, probably $\mathrm{MgAl}_{2} \mathrm{O}_{4}$, was present. Because of the uncertainties inherent in reducing the densities of the equation of state point by $0.02 \pm 0.005$ $\mathrm{g} / \mathrm{cm}^{3}$ to take the impurities into account, further work on this material was discontinued.

\section{Experimental Details}

The machined specimen disks were mounted on ground and polished 1.5-mm-thick driver plates of tungsten alloy $(\mathrm{W}, 90.4 \% ; \mathrm{Ni}, 4.65 \%$; $\mathrm{Cu}, 4.90 \%$; density, $\left.16.9 \mathrm{~g} / \mathrm{cm}^{3}\right)$. Flat and inclined mirrors (with reflecting surfaces toward the direction of the incident shock) were mounted on the assembly (Figure 1) to record the shock arrivals at the specimen-driver interface and at the specimen's free surface. Various details of the technique, which also permits measuring the shock-induced free-surface velocity, were described by Fowles [1967] and Ahrens et al. [1968]. After using an optical lever setup to ensure that the flat mirrors lie within $4^{\prime}$ of arc of planes parallel to the driver-specimen interface and after measuring the inclined mirror angle, contactor pins (E.G.\&G. CA1038) were inserted in the driver plate and the sample was mounted in the semi-expendable assembly shown in Figure 1.

Shocks of different amplitude were driven into a series of specimens by impacting the specimens with flyer plates held in a Lexan plastic sabot [Jones et al., 1966]. The flyer plate was made of the same alloy as the driver plate but was 3.8 $\mathrm{mm}$ thick, and the sabot was accelerated to speeds of 0.3 to $2.3 \mathrm{~km} / \mathrm{sec}$ by a propellant gun $40 \mathrm{~mm}$ in diameter and 8 meters long. The assembly was suspended in a 5600-liter evacuated tank into which the gun tube protrudes. Before firing the projectile in the geometry depicted in Figure 2, the sample assembly was optically aligned with the axis of the gun tube. Details of this apparatus, the projectiles, and the alignment 
and calibration procedures will be described in a forthcoming paper.

Because we employed the impedance-match method [Walsh and Christian, 1955] in the experiments to obtain the high-pressure shock state in the sample, the velocity of the flyer plate and hence the velocity of the projectile had to be measured. This was accomplished during the time that the projectile traveled the final $50 \mathrm{~cm}$ of the barrel. The projectile successively intersected three $\mathrm{He}-\mathrm{Ne}$ laser beams that were oriented perpendicular to the bore axis and were detected by three photodiodes. The first two beams were brought through the barrel via holes $3 \mathrm{~mm}$ in diameter and the third beam was placed $1 \mathrm{~cm}$ from the gun-tube muzzle. After flying free in the vacuum chamber for a distance of $50 \mathrm{~cm}$, the projectile struck the electrical trigger pins affixed to the target. The photodiode signals produced by interruption of the laser beams and a signal produced by an external circuit upon the projectile's impact with the contactor pins were used to turn three timeinterval counters on and off. The counters provided projectile travel times between the four stations to an accuracy of $\pm 0.1 \mu$ sec. The distances required to calculate average projectile velocity within the three time intervals were separately measured to $\pm 0.1 \mathrm{~mm}$, which provided an over-all precision of $\pm 0.2 \%$ for the velocity between stations. A raster oscilloscope, triggered by the first photodiode, which later displayed the pin-contactor closure signal, provided redundant timing data.

To measure the velocity of the shocks induced in the sample upon projectile impact, the times between destruction of the mirror reflecting coatings were obtained by using an image converter camera (TRW model 1D). The optical path from the xenon flash tube (ignited when

TABLE 2. Hugoniot Data for Forsterite

\begin{tabular}{|c|c|c|c|c|c|c|c|c|}
\hline Shot & $\begin{array}{l}\text { Thickness, } \\
\mathrm{mm}\end{array}$ & $\begin{array}{c}\text { Initial } \\
\text { Density, } \\
\mathrm{g} / \mathrm{cm}^{\mathbf{3}}\end{array}$ & $\begin{array}{l}\text { Projectile } \\
\text { Velocity, } \\
\mathrm{km} / \mathrm{sec}\end{array}$ & $\begin{array}{c}\text { Elastic } \\
\text { Precursor } \\
\text { Velocity, } \\
\mathrm{km} / \mathrm{sec}\end{array}$ & $\begin{array}{c}\text { Shock } \\
\text { Velocity, } \\
\mathrm{km} / \mathrm{sec}\end{array}$ & $\begin{array}{r}\text { Particle } \\
\text { Velocity, } \\
\text { km/sec }\end{array}$ & $\begin{array}{c}\text { Pressure, } \\
\text { Mb }\end{array}$ & $\begin{array}{l}\text { Density, } \\
\mathrm{g} / \mathrm{cm}^{\mathbf{3}}\end{array}$ \\
\hline A82 & 4.80 & 2.634 & $\begin{array}{r}1.201 \\
\pm 0.005\end{array}$ & $\begin{array}{r}5.91 \\
\pm .03\end{array}$ & $\begin{array}{r}4.19 \\
\pm 0.05\end{array}$ & 1.01 & 0.113 & 3.463 \\
\hline A70 & 4.83 & 2.627 & $\begin{array}{r}1.17 \\
\pm .04\end{array}$ & $\begin{array}{c}\mathbf{5 . 8 2 *} \\
\pm 0.08\end{array}$ & $\begin{array}{r}4.21 \\
\pm 0.04\end{array}$ & 1.03 & 0.116 & 3.489 \\
\hline A75 & 4.83 & 2.633 & $(1.42)$ & $\begin{array}{r}5.83 \\
\pm 0.05\end{array}$ & $\begin{array}{r}4.98 \\
\pm 0.08\end{array}$ & 1.21 & 0.159 & 3.469 \\
\hline A68 & 6.27 & 3.093 & $\begin{array}{r}1.11 \\
\pm 0.04\end{array}$ & $\begin{array}{r}6.96 \\
\pm 0.12\end{array}$ & $\begin{array}{r}6.83 \\
\pm 0.12\end{array}$ & 0.855 & 0.181 & 3.536 \\
\hline A60 & 6.26 & 3.094 & $\begin{array}{r}1.107 \\
\pm 0.005\end{array}$ & $\begin{array}{r}7.03 \\
\pm .06\end{array}$ & $\begin{array}{r}6.48 \\
\pm 0.06\end{array}$ & 0.854 & 0.172 & 3.567 \\
\hline A104 & 4.20 & 3.087 & $\begin{array}{r}1.161 \\
\pm 0.006\end{array}$ & $\begin{array}{r}8.22 \\
\pm 0.04\end{array}$ & $(6.74)$ & 0.897 & 0.187 & 3.561 \\
\hline A90 & 4.54 & 3.117 & $\begin{array}{l}1.305 \\
\pm 0.01\end{array}$ & $\begin{array}{r}8.48 \\
\pm 0.45\end{array}$ & $\begin{array}{r}7.13 \\
\pm 0.14\end{array}$ & 0.995 & 0.221 & 3.623 \\
\hline A105 & 4.20 & 3.119 & $\begin{array}{r}1.285 \\
\pm 0.007\end{array}$ & $\begin{array}{r}9.5 \\
\pm 0.5\end{array}$ & (7.28) & 0.975 & 0.222 & 3.602 \\
\hline A65 & 6.25 & 3.104 & $\begin{array}{r}1.53 \\
\pm 0.02\end{array}$ & $\begin{array}{r}7.62 \\
\pm 0.34\end{array}$ & $\begin{array}{r}7.47 \\
\pm 0.04\end{array}$ & 1.16 & 0.269 & 3.674 \\
\hline A91 & 4.57 & 3.102 & $\begin{array}{r}1.77 \\
\pm 0.02\end{array}$ & $\begin{array}{r}8.29 \\
\pm 0.13\end{array}$ & $\begin{array}{r}7.33 \\
\pm 0.09\end{array}$ & 1.35 & 0.307 & 3.801 \\
\hline A93 & 4.54 & 3.115 & $\begin{array}{r}2.132 \\
\pm 0.007\end{array}$ & $\begin{array}{r}8.50 \\
\pm 0.14\end{array}$ & $\begin{array}{r}7.34 \\
\pm 0.06\end{array}$ & 1.63 & 0.373 & 4.004 \\
\hline $\begin{array}{l}\text { A101 } \\
\text { A89 }\end{array}$ & $\begin{array}{l}4.55 \\
4.43\end{array}$ & $\begin{array}{l}3.113 \\
3.118\end{array}$ & $\begin{array}{l}(2.2) \\
(0.315)\end{array}$ & $\begin{array}{c}(8.77) \\
5.2 \\
\pm 0.3\end{array}$ & $t$ & 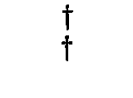 & $\begin{array}{l}\dagger \\
t\end{array}$ & \\
\hline
\end{tabular}

Values in parentheses indicate a single measurement.

- Particle velocity obtained from free-surface motion of $0.031 \mathrm{~km} / \mathrm{sec}$ gives elastic shock state; stress, $0.0048 \mathrm{Mb}$; density, $2.655 \mathrm{~g} / \mathrm{cm}^{3}$.

$\uparrow$ Second shock present but not recorded. 


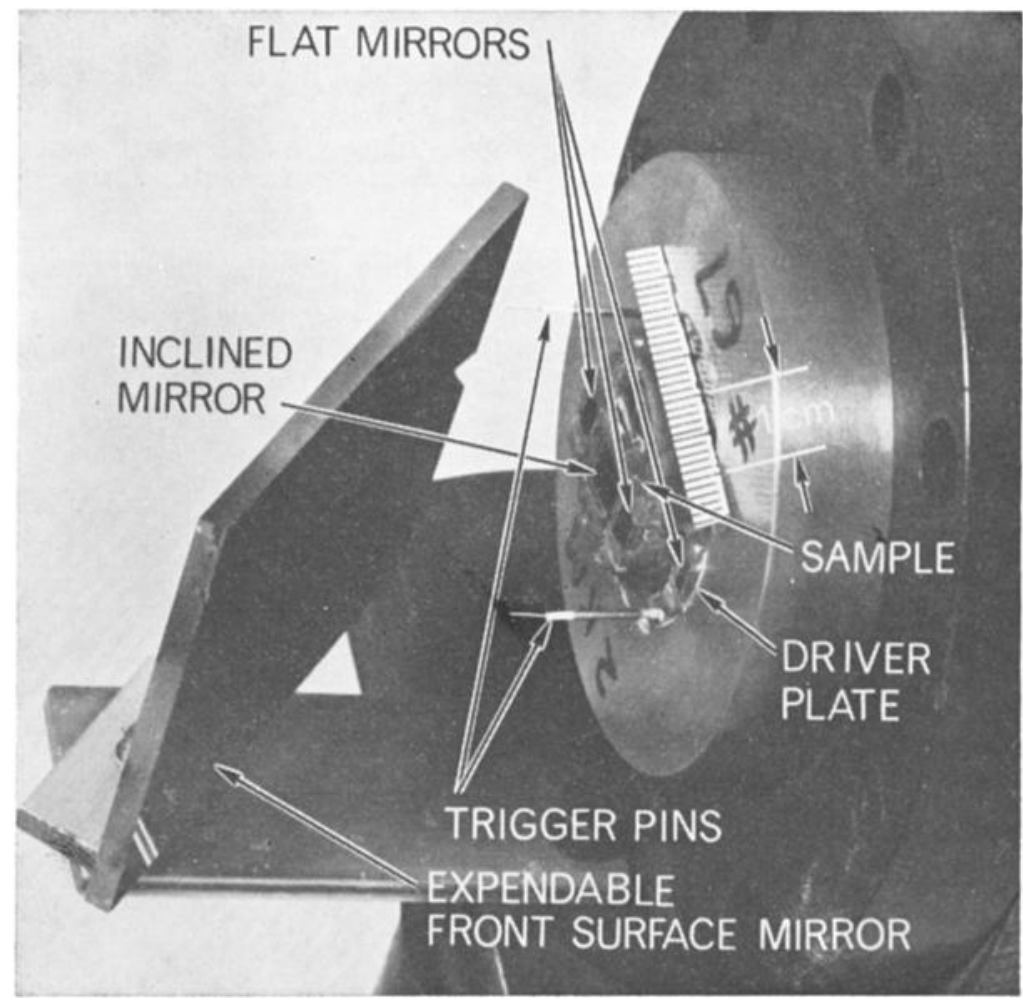

Fig. 1. Forsterite target assembly. Expendable front surface mirror transmits xenon flash tube illumination to flat and inclined mirrors and transmits light reflected from target mirrors to streak camera. Electrical contactor pins, activated upon projectile impact from left, actuate sweep of image converter streak camera.

the projectile passes the third laser beam) extended via an expendable mirror to the target, then to the expendable mirror, and then to an objective lens. The objective lens focused the image of the rear target surface on a slit that was external to the vacuum tank. The image converter camera, which was also focused on the slit, was sweep-triggered by the pin closure. A resulting streak record showing the typically rather ragged elastic precursor and the smooth following deformational, or main, shock in fosterite is shown in Figure 3. The reader is referred to papers by Fowles [1967] and Ahrens et al. [1968] for the various details of such records.

Application of image-converter streak cameras to precision shock transit-time measurements has previously been limited by the lack of suitable calibration methods for streak writing rates. Initially we used the oscilloscope calibration technique described by Ahrens and Spetzler [1969] for this purpose. A second method used in the early experiments (prior to shot A70) was to time, by single sweep oscillography, the duration of the 'shutter' pulse that turns on the flow of electrons in the image converter tube for a time corresponding to the camera sweep interval. This procedure is easier to carry out than the Ahrens and Spetzler's [1968] method and yields an average writing rate over the streak length that is accurate to $\pm 0.5 \%$. For later shots the intensity-modulated laser beam technique, depicted in Figure 2, was employed, which permitted the camera writing rate to be obtained to within $\pm 0.17 \%$ at any point along the streak record (Figure 3). Davies [1970] has recently described a similar method.

\section{Resutrs}

The streak records obtained in the experiments performed on both the $2.6-$ and the $3.1-\mathrm{g} / \mathrm{cm}^{3}$ forsterite showed that the initial shock-wave arrival (loss of mirror reflectivity) in the flat 


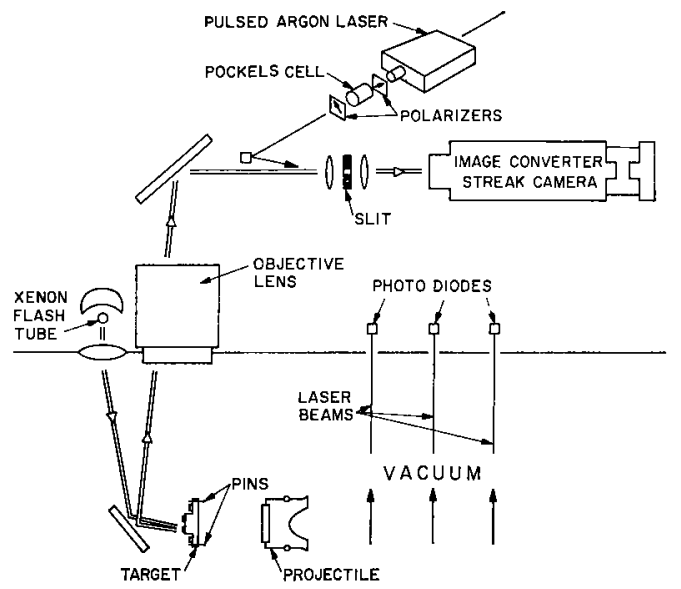

Fig. 2. Diagrammatic sketch of equation of state experiment. Projectile travels in vacuum. Velocity is determined by the projectile's cutting three laser beams and striking the contactor pins. Successive interaction with mirrors of resulting shock in sample, recorded as a function of time with streak camera, determines shock velocity. Pockels cell intensity modulates pulsed laser, providing timing marks for streak camera. mirrors occurred well before the onset of appreciable free-surface motion was detectable in the inclined mirror image (Figure 3). Because it was also observed that the onset of free-surface motion coincided in time with a second usually complete loss of reflectivity in the flat mirrors, we inferred that an elastic shock or precursor was present in all the experiments. The fact that the free-surface velocities, which were measured with inclined mirrors, were approximately equal to twice the final shock particle velocity supported this conclusion. The elastic precursor is thought to represent a one-dimensional compression wave in which internal rearrangement of the material has not yet occurred. The second very much stronger shock corresponds to achievement of a state in which the material has undergone internal deformation and the compression is no longer one dimensional on a microscopic scale.

The motion of the free surface associated with the precursor arrivals in the $2.6-\mathrm{g} / \mathrm{cm}^{3}$ sample was just barely detectable. For shot A70, a precursor-induced free-surface velocity of $\mathbf{0 . 0 6 2}$ $\mathrm{km} / \mathrm{sec}$ was measured. Assuming that the free-

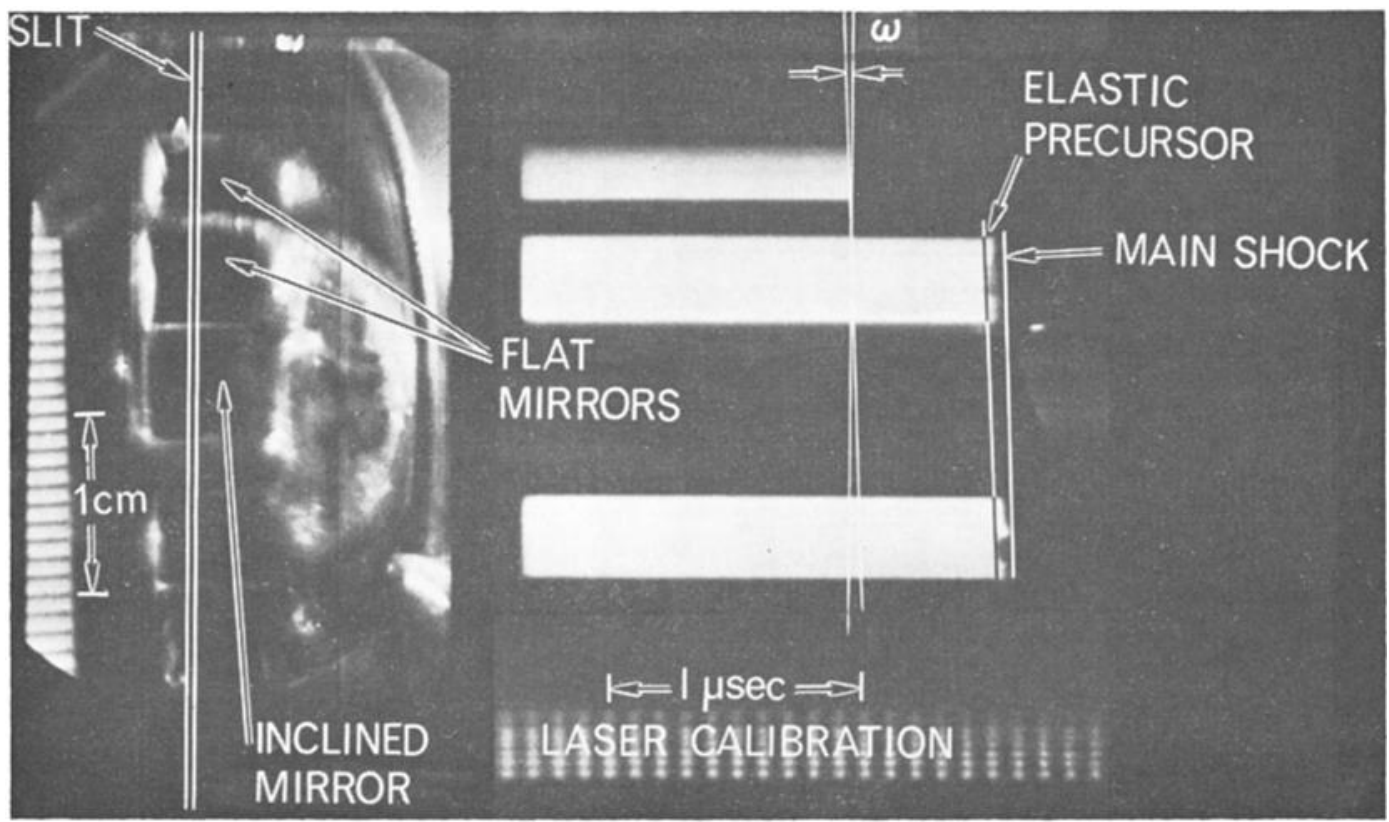

Fig. 3. Streak camera record obtained from rear surface of forsterite target assembly upon being impacted with flyerplate traveling at $2.1 \mathrm{~km} / \mathrm{sec}$. (Left) Image of target assembly as viewed statically through streak camera showing position of slit with respect to reflecting mirrors. (Right) Streak record showing irregular arrival of elastic precursor, followed by main shock. 
surface velocity represents approximately twice the precursor particle velocity, we can calculate a precursor amplitude of $\sim 0.0048 \mathrm{Mb}$. The surprising lack of a measurable amplitude from the precursor free-surface velocity for the denser $3.1-\mathrm{g} / \mathrm{cm}^{3}$ forsterite forced us to conclude that the precursor amplitudes at the free surface were less than $\sim 0.005 \mathrm{Mb}$. The inclined mirror angles used on both classes of samples were similar. A maximum stress offset of the deformational Hugoniot above the 'hydrostatic' curve of $0.0022 \mathrm{Mb}$ was calculated from simple elastoplastic theory [Fowles, 1961] with a Poisson's ratio of 0.24 . We infer from the apparent rapid attenuation of the elastic precursor (discussed below) that even this 'maximum' value for strength effect is probably too high and that the deformational shock states achieved are effectively hydrostatic.

For some of the shots appreciable correction for shock tilts were applied in calculating the shock velocities by using the relations

$$
\tan \epsilon=M \tan \omega V_{a} / W
$$

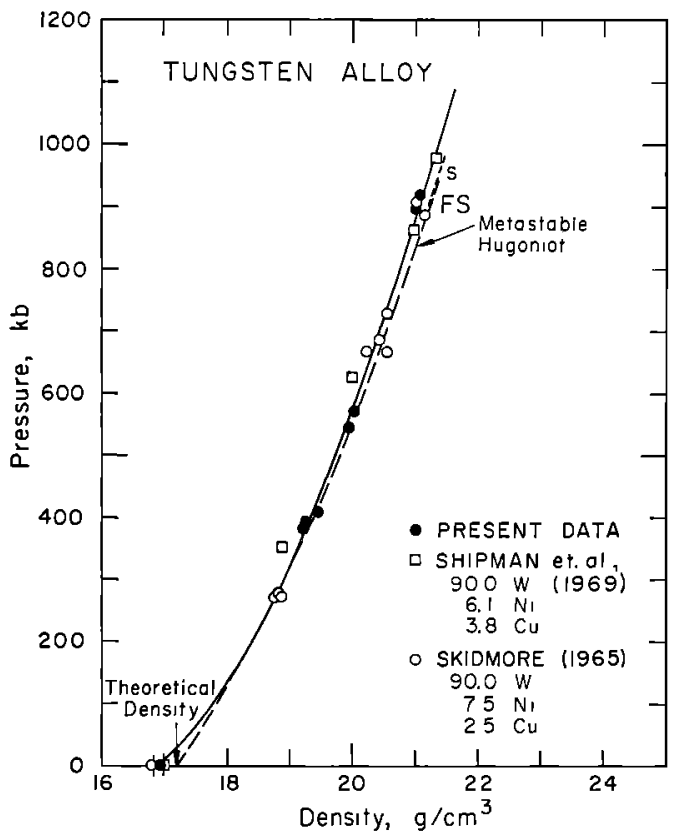

Fig. 4. Tungsten alloy Hugoniot data used for reduction of forsterite shots. Metastable Hugoniot indicates theoretical curves for samples having no porosity with compositions corresponding to $\boldsymbol{S} k i d-$ more [1965] (S) and Shipman et al. [1969] (FS) data.

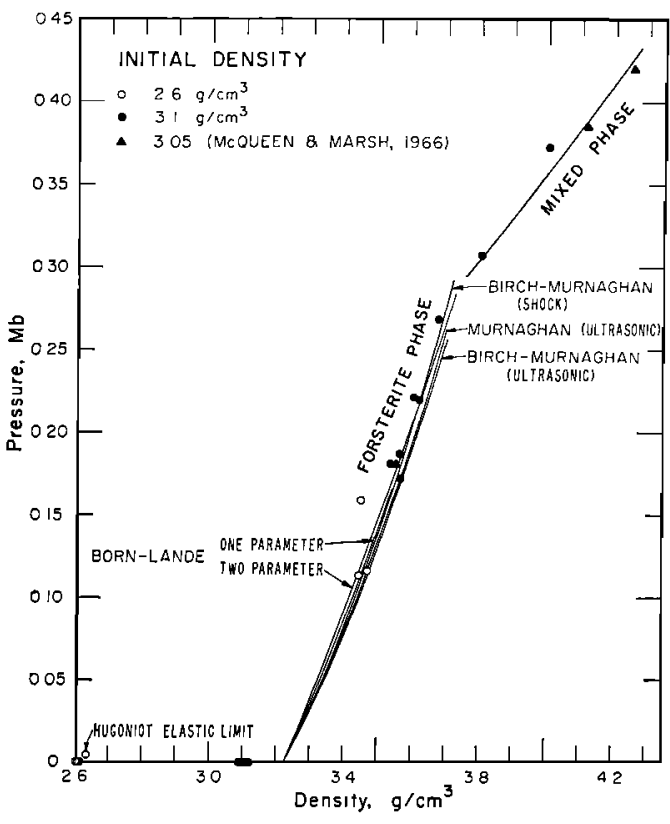

Fig. 5. Hugoniot data for pure forsterite, initial densities 2.6 and $3.1 \mathrm{~g} / \mathrm{cm}^{3}$. Various principal adiabats for forsterite derived from shock and ultrasonic data are shown. Metastable transition, probably from forsterite to post-spinel phase, occurs at $0.280 \pm 0.025 \mathrm{Mb}$.

$$
V=V_{a} \cos \epsilon
$$

where $\epsilon$ is the velocity component along the slit of the shock tilt angle with respect to the initial free surface, $M$ is the magnification of the film, and $W$ is the streak camera writing rate. The term $\omega$ is defined in Figure 3, and $V_{a}$ and $V$ are the apparent and actual shock velocities, respectively. In future experiments we expect also to correct for tilt in the direction perpendicular to the slit. The varying degrees of shock tilt experienced are reflected in the uncertainties assigned to the shock velocities in Table 2.

The final deformational shock states were calculated by using the impedance-match method and the Rankine-Hugoniot equations. The Hugoniot of the tungsten alloy flyer and the driver plate standard material used in the reduction of the data is shown in Figure 4. The measurements on this tungsten alloy will be reported separately.

In the analysis of the $2.6-\mathrm{g} / \mathrm{cm}^{3}$ forsterite data a precursor particle velocity of $0.031 \mathrm{~km} / \mathrm{sec}$ 
and a precursor amplitude calculated from the observed shock velocity were assumed for the state in which the deformational or second shock wave impinged. For the denser $3.1-\mathrm{g} / \mathrm{cm}^{3}$ forsterite the second shock was assumed to be incident into material with zero initial velocity and pressure.

The major uncertainty in projectile velocity, and hence particle velocity in the shock state, arises not from the uncertainty in the absolute measurements of velocity between stations $( \pm 0.2 \%)$, but from the uncertainty in extrapolating the velocity to the time of impact over the last $50 \mathrm{~cm}$ of projectile flight. For shots fired before A90 both minor accelerations and decelerations of the projectile were measured in the last meter of travel. Later shots employing heavier projectiles (90 grams) all showed that the projectile was accelerating all the way to the target. This regularity reduced uncertainties where timing data from one of the stations were not obtained.

The resulting Hugoniot data are plotted in Figure 5 in relation to the pressure-density curves inferred from ultrasonic data. It is clear that the data for the $2.6-\mathrm{g} / \mathrm{cm}$ material (especially shot A75) are more scattered. Impurities may account for the scattering. Because the adiabats derived from the Hugoniot data are in acceptable agreement with the ultrasonic curves below $200 \mathrm{~kb}$, finite strength effects, at least of a gross sort, are not measurably present. The reduced data for the equation of state in the forsterite regime (below $\sim 0.280 \mathrm{Mb}$ ) are discussed below. Above $0.280 \pm 0.025 \mathrm{Mb}$ the present Hugoniot data, when taken with points obtained by McQueen and Marsh [given in Anderson and Kanamori, 1968], clearly indicate the onset of a region of anomalous compression that undoubtedly corresponds to a phase change taking place in the forsterite. The one low-pressure point obtained by McQueen and Marsh, which also closely fits the present data, supports this conclusion. The crystal structure of this highpressure phase is not actually known, but the pressure at which the transition begins under shock suggests that forsterite is transforming to a phase in which the silicon ions are octahedrally coordinated by oxygen, although the onset of an overdriven olivine to spinel transition cannot be ruled out. At higher shock pressures the data of McQueen et al. [1967] indicate that a denser- than-spinel phase forms under shock compression. Ringwood and Reid [1968], on the basis of highpressure quenching experiments on analog compounds and on crystal-chemical considerations, suggested that the $\mathrm{K}_{2} \mathrm{NiF}_{4}$ or $\mathrm{Sr}_{2} \mathrm{PbO}_{4}$ structure will be assumed by this phase. Analysis of the Los Alamos high-pressure shock data for dunites and forsterite are consistent with zero-pressure densities of 4.1 and $4.0 \mathrm{~g} / \mathrm{cm}^{3}$ for these structures [Ahrens et al., 1969]. The present shock-induced transition pressure of $0.280 \pm 0.025 \mathrm{Mb}$ (shock temperature $\sim 160^{\circ} \mathrm{C}$ ) could be taken as an upper bound to the forsterite-post spinel phase transition pressure. Because of the low shock temperatures the transition is probably reactionrate limited. Anderson [1967] and Ringwood [1969] have suggested that this so-called post spinel phase is the predominant mineral of the lower mantle.

\section{Elastic Precursors}

The behavior of the elastic precursor observed in the present experiments on the $3.1-\mathrm{g} / \mathrm{cm}^{3}$ forsterite is sufficiently unusual so as to deserve some comment. Examination of the apparent precursor velocities $V_{10}$ for the denser forsterite gives a surprisingly random series of values. In contrast, the precursor wave velocity for the $2.6 \mathrm{-g} / \mathrm{cm}^{3}$ material (Table 2) is observed to be

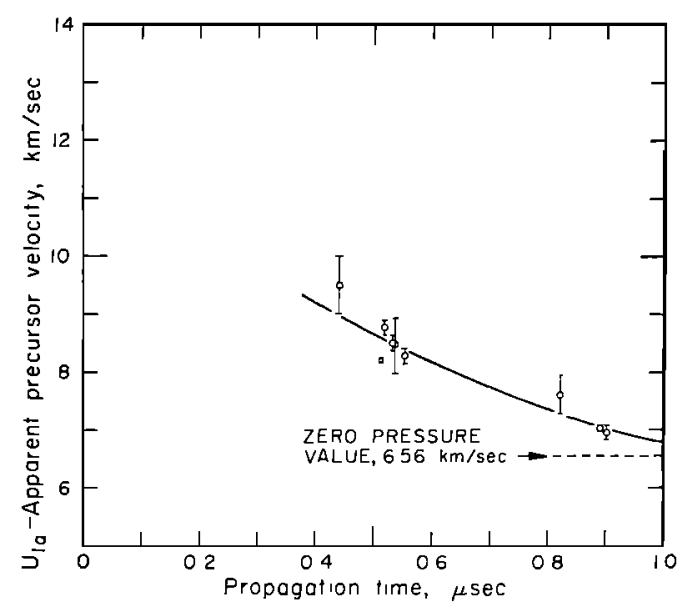

Fig. 6. Apparent precursor velocity versus shock propagation time for $3.1-\mathrm{g} / \mathrm{cm}^{3}$ forsterite. A relaxation process appears to be taking place in which precursor velocity approaches zeropressure longitudinal velocity with an apparent characteristic time of less than $1 \mu$ sec. 
nearly constant at $5.82-5.91 \mathrm{~km} / \mathrm{sec}$. (The range of pressures and specimen thicknesses for these samples is not large.) Since the sample thicknesses for the $3.1-\mathrm{g} / \mathrm{cm}^{3}$ material varies from 4.2 to $6.3 \mathrm{~mm}$ the existence of a stress relaxation effect could be indicated by plotting the parameter $U_{1_{a}}$ versus propagation time, as in Figure 6. This representation orders these data to a remarkable degree. At long propagation times the precursor velocity approaches the longitudinal elastic velocity $6.56 \mathrm{~km} / \mathrm{sec}$ of the initially porous material (R. N. Schock, private communication). The time constant for the relaxation process is apparently less than $1 \mu$ sec. This effect appears to be markedly different than the effect observed by Wackerle [1962] and Ahrens and Duvall [1966] in single and polycrystalline quartz, respectively. For the nonporous quartz, to first order, the shock velocity remains constant and the apparent particle velocity decays. Although not detectable in these experiments, it is likely that the particle velocity in the forsterite precursor may also decay.

\section{Equation of State Parameters}

We have reduced the shock data below $0.280 \mathrm{Mb}$ (Table 2) to various adiabats, isotherms, and metastable Hugoniot forms of the equation of state by the methods outlined in Ahrens et al. [1969]. Because the ultrasonic data are related directly to the adiabats, they are discussed below. Because the two groups of samples differed significantly in their initial bulk density $\left(2.6\right.$ and $\left.3.1 \mathrm{~g} / \mathrm{cm}^{3}\right)$, the shock data were reduced specifically so as to take the different porosities into account. Rather than average initial densities and perform further reductions from a mean analytic Hugoniot curve, we calculated the pressure along the principal adiabat (or isentrope) for each density achieved along the Hugoniot. The principal adiabat is the adiabat centered at ambient pressure and at $25^{\circ} \mathrm{C}$. For a Hugoniot state at a pressure and density $p_{H}$ and $\rho$, respectively, the adiabatic pressure at that density is given by [Ahrens et al., 1969]

$$
\begin{aligned}
p_{a} & =p_{H}-\gamma \rho \\
\cdot & {\left[p_{H}\left(1 / \rho_{00}-1 / \rho\right) / 2-\int_{\rho_{0}}^{\rho} p_{a} d \rho / \rho^{2}\right] }
\end{aligned}
$$

where $\rho_{00}$ is the initial bulk density of the sample, $\rho_{0}$ is the zero-pressure crystal density, and $\gamma=$ $\alpha K_{S} / \rho C_{p}$ is the thermodynamic Grüneisen parameter. Here $\alpha$ is the thermal expansion, $K_{S}$ is the adiabatic bulk modulus, and $C_{p}$ is the specific heat at constant temperature. The assumption that $\gamma$ depends only on volume is implicit in equation 3 .

Because of the present lack of pertinent data or an adequate theory describing the variation of $\gamma$ with pressure and temperature in silicates when they are below their Debye temperature, we assumed the volume dependence of $\gamma$ to be given by

$$
\gamma=\gamma_{0}\left(\rho_{0} / \rho\right)^{n}
$$

The resultant series of adiabatic points were fit to the two-parameter Birch-Murnaghan, BornLande, and Born-Mayer forms of the equation of state given by

$$
\begin{gathered}
p=\frac{3}{2} K_{0}\left[\left(r_{0} / r\right)^{7}-\left(r_{0} / r\right)^{5}\right] \\
\cdot\left\{1-\xi\left[\left(r_{0} / r\right)^{2}-1\right]\right\} \\
p=\frac{3 K_{0}}{n-1}\left[\left(\frac{r_{0}}{r}\right)^{n+3}-\left(\frac{r_{0}}{r}\right)^{4}\right] \\
p=\frac{3 K_{0}}{\left(r_{0} / \rho\right)-2}\left[\left(\frac{r_{0}}{r}\right)^{2}\right. \\
\left.\cdot\left[\exp \left(r_{0}-r\right) / \rho\right]-\left(\frac{r_{0}}{r}\right)^{4}\right]
\end{gathered}
$$

where $K_{0}$ is the appropriate zero-pressure bulk modulus and $r_{0}$ and $r$ are characteristic lengths in the initial and compressed material, respectively. Hence $\left(\rho / \rho_{0}\right)^{1 / 3}=r_{0} / r$. The zero-pressure value of $\partial K / \partial P$ is related to the parameters $\xi, n$, and $r_{0} / \rho$ by

$$
\begin{aligned}
& \partial K / \partial P=4-4 \xi / 3 \\
& \partial K / \partial P=(n+7) / 3 \\
& \partial K / \partial P=\frac{14-\left(1+r_{0} / \rho\right)\left(2+r_{0} / \rho\right)}{6-3 r_{0} / \rho}
\end{aligned}
$$

Equations 5-7 are similar in form and all yield similar pressure-density curves for values of $r_{0} / r \approx 1.2$. Equation 5 is valid to third-order Eulerian strain [Thomsen, 1970] and can be used to represent an adiabatic curve if the strains are defined in an adiabatic sense. Equations 6 and 7 are derived from a simple static ionic centrosymmetric potential model of a crystal 


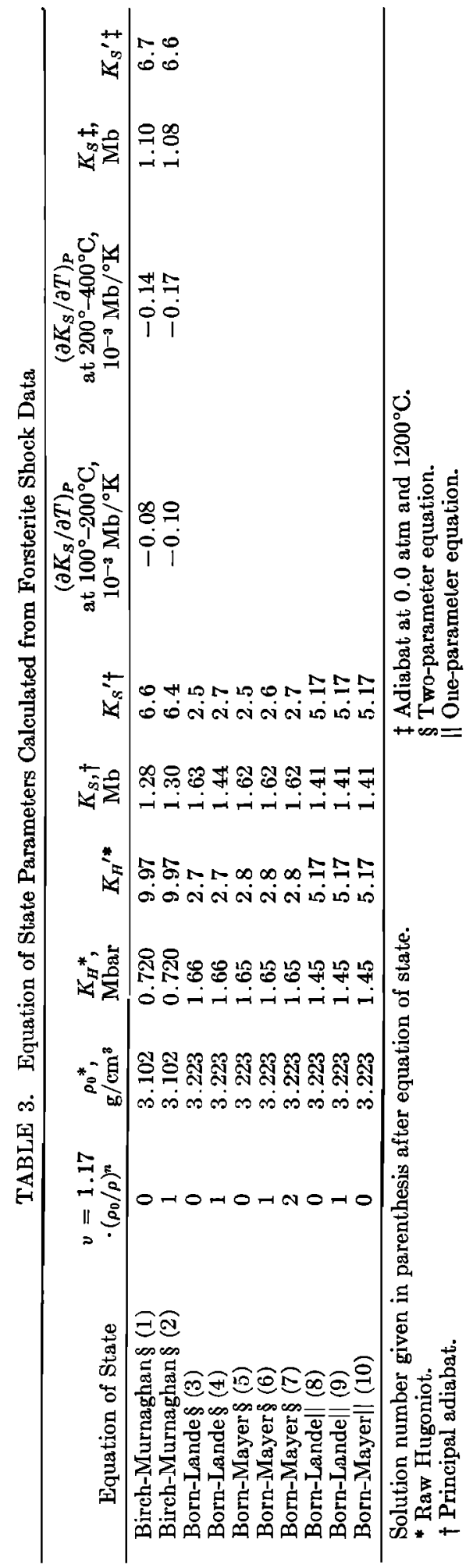

and are strictly appropriate for the $0^{\circ} \mathrm{K}$ isotherm. These should be considered as representing only an empirical pressure-density relation for other thermodynamic curves, such as adiabats. The application of equations 6 and 7 to oxides has recently been discussed by Anderson and Anderson [1970]. For application to forsterite, more serious objections to the use of equations 6 and 7 are that the forces between ions are noncentral and the $\mathrm{Si}^{4+-} \mathrm{O}^{-}$bond in tetrahedrally coordinated silicates is known to be partially ionic [Bloomfield et al., 1961]. Hence at low pressure the $\left(r_{0} / r\right)^{4}$ term, which reflects Coulombic type attractions, is likely to be in error, and at high pressures bond asymmetries will result in poor representations of the equation of state.

The suitability of different equations of state to the fitting of slıock-wave data for a silicate, such as forsterite, is demonstrated by results summarized in Table 3 . The zero-pressure values of $K_{S}$ and $\left(\partial K_{s} / \partial P\right)_{S}$ are known from the ultrasonic measurements of Kumazawa and Anderson [1969] and Graham and Barsch [1969] to be $1.29 \mathrm{Mb}$ and 5.0 to 5.4, respectively. Except for solutions 1 and 2, obtained with the BirchMurnaghan equation, large variations from the ultrasonic values are indicated in Table 3. Although the Birch-Murnaghan solutions agree well with the zero-pressure bulk modulus, the values of $\left(\partial K_{s} / \partial P\right)_{s}$ of 6.6 and 6.4 for $n=0$ and $n=1$ (equation 4) obtained from the shock data are too high. The agreement with the ultrasonic data is better, however, than the agreement obtained from the Born-Lande or Born-Mayer two-parameter equation. The closer agreement of $K_{s}$ and $\left(\partial K_{s} / \partial P\right)_{s}$ obtained by fitting the shock-wave data with the Eulerian Birch-Murnaghan equation is believed to be not accidental, but rather to result from the fact that the exponents in this equation are fixed, which has the effect of more seriously constraining the curvature of the resulting pressure-density curve. As shown by solutions 8-10, when the value of $\left(\partial K_{S} / \partial P\right)_{s}$ is fixed at the ultrasonic value, the Born-Lande and Born-Mayer equations of state give values of $K_{S}$ that are in closer agreement with the ultrasonic values. It is clear from Table 3 that $K_{S}$ and $\left(\partial K_{s} / \partial P\right)_{S}$ are affected only slightly by variation in the assumed value of $n$ in equation 4 .

The temperatures along the Hugoniot of $\mathrm{Mg}_{2} \mathrm{SiO}_{4}$ in the forsterite phase, which we calcu- 
lated (e.g., $160^{\circ} \mathrm{C}$ at $390 \mathrm{~kb}$ ) for the pressure range of the data are considerably lower than the temperatures of general geophysical interest. Shock temperatures were calculated by the method outlined in Ahrens et al. [1969]. The relatively low temperatures obtained result from the low value of the Grüneisen parameter and the incompressibility of forsterite. The pressuredensity states of a series of adiabats centered at zero-pressure and high temperatures were calculated by using the present Hugoniot data and the zero-pressure specific heat and the thermal expansion data for forsterite [Clark, 1966]. Details of this type of calculation in which both the temperature variation of the specific heat and thermal expansion coefficient are taken into account are described by Davies and Ahrens (unpublished data, 1970). The values -0.8 and $-0.10 \mathrm{~kb} /{ }^{\circ} \mathrm{C}$ for $\left(\partial K_{s} / \partial T\right)_{P}$ that were calculated in the temperature interval $100^{\circ}-200^{\circ} \mathrm{C}$ are somewhat lower than the values -0.14 and -0.17 $\mathrm{kb} /{ }^{\circ} \mathrm{C}$ that were calculated for the interval $200^{\circ}$ $400^{\circ} \mathrm{C}$. The values for the interval $200^{\circ}-400^{\circ} \mathrm{C}$ are in good agreement with the ultrasonic values of -0.150 and $-0.176 \mathrm{~kb} /{ }^{\circ} \mathrm{C}$ that were reported by Kuma:awa and Anderson [1969] and Graham and Barsch [1969]. The values of $K_{S}$ and $\left(\partial K_{S} / \partial P\right)_{s}$ for the adiabat centered at zero pressure and $1200^{\circ} \mathrm{C}$ are given in Table 3.

Acknowledgments. We appreciate the contributions of W. Miller. F. Lehner, and J. L. Blayney to the design of the electronics and optics, the help of D. Tanner, D. Johnson, H. P. Liu, and Rex Gibbons with the experiments, and the assistance of G. Davies with the reduction of data. We thank D. L. Anderson for reviewing the manuscript.

This research was supported by the National Science Foundation under grant GA 1650 .

\section{REFERENCES}

Ahrens, T. J., D. I. Anderson, and A. E. Ringwood, Equation of state and crystal structures of high-pressure phases of shocked silicates and oxides, Rev. Geophys., 7, 667-707, 1969.

Ahrens, T. J., and G. E. Duvall, Stress relaxation behind elastic shock waves in rocks, J. Geophys. Res., 71 , 4349, 1966.

Ahrens, T. J., W. H. Gust, and E. B. Royce, Material strength effect in the shock comprestion of alumina, J. Appl. Phys., 39, 4610-4616, 1968 .

Ahrens, T. J., and C. F. Petersen, Shock-wave data and the study of the earth, in The Application of Modern Physics to the Earth and Planetary
Interiors, edited by S. K. Runcorn, pp. 449-464, Interscience, New York, 1969.

Ahrens, T. J., and H. Spetzler, Calibration of an image-converter streak camera, Rev. Sci. Instrum., 40, 354, 1969.

Ahrens, T. J., and Y. Syono, Calculated mineral reactions in the earth's mantle, $J$. Geophys. Res., 72, 4181-4188, 1967.

Anderson, D. L., Phase changes in the upper mantle, Science, 16\%, 1165-1173, 1967.

Anderson, D. L., Petrology of the mantle, in Mineralogy of the Manlle, Mineralogical Society of America, to be published, 1970.

Anderson, D. L., and O. L. Anderson, The bulk modulus-volume relationship for oxides, $J$. Geophys. Res., 75, 3494, 1970.

Anderson, D. L., and H. Kanamori, Shock-wave equations of state for rocks and minerals, $J$. Gcophys. Res., 79, 6477-6502, 1968.

Birch, F., Elasticity and constitution of the earth's interior, J. Geophys. Res., 57, 227-286, 19.52.

Bloomfield, P., A. W. Lawson, and C. Reg, Crystal field splitting and covalent bonding in $\mathrm{Fe}^{++}$ silica te garnets, J. Chem. Phys., 34, 749-756, 1961.

Bridgman, P. W., Rough compression of 177 substances to $40,000 \mathrm{~kg} / \mathrm{cm}^{2}$, Proc. Amer. Acad. Arls. Sci., 76, 71-87, 1948.

Clark, S. P., Jr. (Ed.), Handbook of Physical Constants, Geol. Soc. Amer. Mem. 97, 1966.

Davies, T. J., Technique for optically calibrating streak cameras, Rev. Sci. Instrum., 41, 920-922, 1970.

Fowles, G. R., Shock wave compression of hardened and annealed 2024 aluminum, J. Appl. Phys., 32, 1475-1487, 1961.

Fowles, R., Dynamic compression of quartz, J. Geophys. Res., 72, 5729-5747, 1967.

Graham, E. K., Jr., and G. R. Barsch, Elastic constants of single-crystal forsterite as a function of temperature and pressure, J. Geophys. Res., 74, 5949-5960, 1969.

Hughes, D. S., and R. G. McQueen, Density of basic rocks at very high pressures, Trans. $A G U$, 39, 959-965, 1958.

Jones, A. H., W. M. Isbell, and C. J. Maiden, Measurement of the very-high-pressure properties of materiuls using a light-gas gun, J. Appl. Phys., 37, 3493-3499, 1966.

Kumazawa, M., and O. L. Anderson, Elastic moduli, pressure derivatives, and temperature derivatives of single-crystal olivine and singlecrystal forsterite, J. Geophys. Res., 74, 5961-5972, 1969.

McQueen, R. G., S. P. Marsh, and J. N. Fritz, Hugoniot equation of state of twelve rocks, J. Geophys. Res., 7\&, 4999-5036, 1967.

Ringwood, A. E., Phase transformations in the mantle, Earth Planet. Sci. Letl., 5, 401-412, 1969.

Ringwood, A. E., and A. Major, The system $\mathrm{Mg}_{2} \mathrm{SiO}_{4}-\mathrm{Fe}_{2} \mathrm{SiO}_{4}$ at high pressures and temperatures, Phys. Earth Planet. Interiors, 3, 89-108, 1970.

Ringwood, A. E., and A. F. Reid, High-pressure 
polymorphs of olivines: The $\mathrm{K}_{2} \mathrm{NiF}_{4}$ type, Earth Planet. Sci. Lett., 5, 67-70, 1968.

Shipman, F. H., W. M. Isbell, and A. H. Jones, High-pressure Hugoniot measurements for several Nevada test site rocks, Final Reporl, DASA 2214, General Motors Materials and Structures Laboratory, Warren, Mich., 1969.

Skidmore, I. C., Introduction to shock waves in solids, Appl. Mater. Res., 4, 131, 1965.

Thomsen, Leon, On the fourth-order anharmonic equation of state of solids, J. Phys. Chem. Solids, in press, 1970.
Trunin, R. F., V. I. Gon'shakova, G. V. Simakov, and N. E. Galdin, A study of rocks under high pressures and temperatures created by shock compression, Izv. Earth Phys. Ser., no. 9, 1-12, 1966.

Wackerle, J., Shock-wave compression of quartz, J. Appl. Phys., 33, 922-937, 1962.

Walsh, J. M., and R. H. Christian, Equation of state of metals from shock-wave measurements, Phys. Rev., 97, 1544-56, 1955.

(Received April 7, 1970.) 